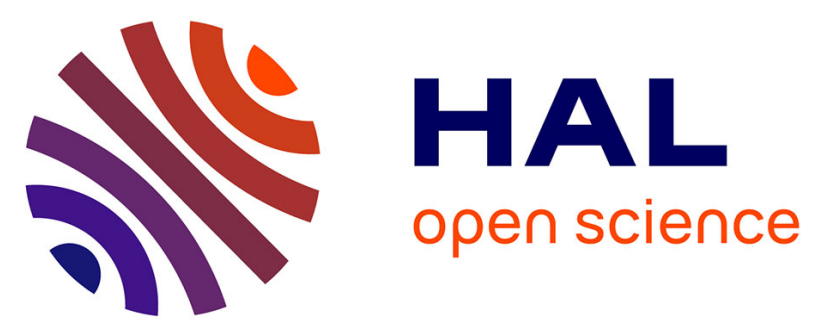

\title{
Microwave, ultrasound, thermal treatments, and bead milling as intensification techniques for extraction of lipids from oleaginous Yarrowia lipolytica yeast for a biojetfuel application
}

Alice Meullemiestre, Cassandra Breil, Maryline Abert-Vian, Farid Chemat

\section{To cite this version:}

Alice Meullemiestre, Cassandra Breil, Maryline Abert-Vian, Farid Chemat. Microwave, ultrasound, thermal treatments, and bead milling as intensification techniques for extraction of lipids from oleaginous Yarrowia lipolytica yeast for a biojetfuel application. Bioresource Technology, 2016, 211, pp.190199. 10.1016/j.biortech.2016.03.040 . hal-02641577

\section{HAL Id: hal-02641577 \\ https://hal.inrae.fr/hal-02641577}

Submitted on 28 May 2020

HAL is a multi-disciplinary open access archive for the deposit and dissemination of scientific research documents, whether they are published or not. The documents may come from teaching and research institutions in France or abroad, or from public or private research centers.
L'archive ouverte pluridisciplinaire HAL, est destinée au dépôt et à la diffusion de documents scientifiques de niveau recherche, publiés ou non, émanant des établissements d'enseignement et de recherche français ou étrangers, des laboratoires publics ou privés. 


\title{
Microwave, ultrasound, thermal treatments, and bead milling as intensification techniques for extraction of lipids from oleaginous Yarrowia lipolytica yeast for a biojetfuel application
}

\author{
Alice Meullemiestre, Cassandra Breil, Maryline Abert-Vian*, Farid Chemat \\ Université d'Avignon et des Pays du Vaucluse, INRA, UMR 408, GREEN Extraction Team, F-84000 Avignon, France
}

H I G H L I G H T S

- Maximize the lipids recovery by various extraction processes and pretreatment.

- Microbial oils extracted were quantified and qualified using GC/MS and HPTLC.

- Extraction by bead milling is the most efficient extraction method.

- The best pretreatment in term of yield is the cold drying under pressure.

- Bead milling extraction is the lower energy-consuming and eco-friendly technique.

\author{
G R A P H I C A L A B S T R A C T
}

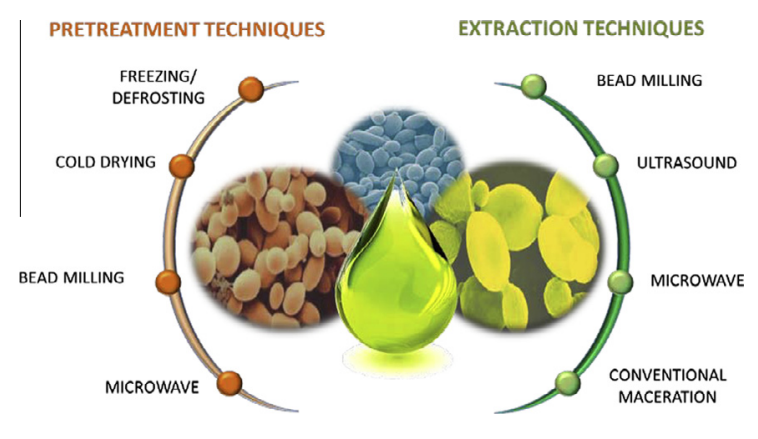

\begin{abstract}
A B S T R A C T
In the present work, two different ways of lipids extraction from Yarrowia lipolytica yeast were investigated in order to maximize the extraction yield. Firstly, various modern techniques of extraction including ultrasound, microwave, and bead milling were tested to intensify the efficiency of lipid recovery. Secondly, several pretreatments such as freezing/defrosting, cold drying, bead milling, and microwave prior two washing of mixture solvent of chloroform:methanol $(1: 2, \mathrm{v} / \mathrm{v})$ were study to evaluate the impact on lipid recovery. All these treatments were compared to conventional maceration, in terms of lipids extraction yield and lipid composition analysis. The main result of this study is the large difference of lipid recovery among treatments and the alteration of lipids profile after microwave and ultrasound techniques.
\end{abstract}

Keywords:

Lipid extraction

Microwave

Ultrasound

Bead milling

Oleaginous microorganisms

\section{Introduction}

The fluctuation of prices due to the rapid depletion of fossil fuel and the drastic control of greenhouse gas emissions has generated an increasing demand of alternative fuel. Biodiesel, fatty acid methyl esters (FAMEs), can be produced from plant seeds, oleaginous microorganisms, or animal's fats. Considered as a promising

\footnotetext{
* Corresponding author.

E-mail address: maryline.vian@univ-avignon.fr (M. Abert-Vian).
}

substitute to fossil fuels, biofuel has the advantage to be renewable, sustainable and more environmental friendly (Rawat et al., 2013). Microbial oils from yeasts offer many advantages such as a faster production, more flexibility in terms of season, less labor, and easier scale-up while phototrophic microalgae are (Huang et al., 2012).

Due to their impressive capacity to accumulate lipid content (up to $20 \%$ of dry cell weights), oleaginous microorganisms such as yeast, bacteria and microalgae are identified as a promising source of feedstock for biodiesel production (Beopoulos and 
Nicaud, 2012). Particularly some yeast strains with optimized culture conditions are able to content up to $70 \% \mathrm{w} / \mathrm{w}$ on dry biomass weight basis (Gao et al., 2013). In oleaginous yeasts, lipids are found mainly in the form of neutral lipids, glycolipids, phospholipids, and free fatty acids (FFA) (Dey and Maiti, 2013). Among them Yarrowia lipolytica is one the most extensively studied "unconventional" microorganisms and was classified as a GRAS (Generally Recognized As Safe) microorganism, therefore can easily be used in industry (Groenewald et al., 2014). Metabolism in Y. lipolytica is now long used for ability to efficiently degrade hydrophobic substrates and high capacity for lipid accumulation (Beopoulos and Nicaud, 2012).

In biodiesel production, oil extraction represents a crucial step and depends of various parameters. The conventional extraction of microbial oil extraction is performed with organic solvent using chloroform-methanol $(1: 2, \mathrm{v} / \mathrm{v})$. This solvent mixture was employed in a current Bligh and Dyer method (Bligh and Dyer, 1959) in the same proportion, which forming a monophasic solvent system, to extract and dissolve lipids. This method is easy to achieve, reproducible, and can readily be performed in large scale (Boyd et al., 2012; Vicente et al., 2009). However, most of yeast strain own ultra-rigid wall cells, thus intracellular extraction of lipids are difficult and organic solvent extraction become not enough efficient to free lipid bodies (Zhu and Jackson, 2015). Innovative techniques including supercritical fluid, pulsed electric fields, microwave and ultrasound-assisted extraction is recognized to facilitate lipids extraction from microorganisms (Bermúdez Menéndez et al., 2014; Chuck et al., 2014; Foltz, 2012; Milanesio et al., 2013). Bead milling, thermal treatment, and microwave prior to solvent extraction can induced cell disruption while minimizing solvent utilization, reduce processing time and as well energy consumption (Florentino de Souza Silva et al., 2014; Montalescot et al., 2015).

This study is divided in three parts. First, we have compared various innovative intensified processes such as bead milling, microwave, and ultrasound versus conventional maceration for extraction of microbial oil from $Y$. lipolytica, in terms of extraction yield and lipid profile characterized by HPTLC and GC/FID. Then, in order to reduce the solvent utilization, energy saving and process time, different pretreatments such as cold drying, freezing/defrosting, bead milling, and microwave was tested prior to conventional extraction with reference mixture of methanol-chloroform $(2: 1$, $\mathrm{v} / \mathrm{v}$ ). The second objective of this study has consisted in the comprehension of extraction phenomenon by mechanical treatment using bead milling. Finally, the different mechanisms of intensified processes (bead milling, microwave, and ultrasound) were detailed and compared for a better understanding of the extraction action in order to have a decision tool.

\section{Materials and methods}

\subsection{Strain, culture, and harvesting conditions}

Oleaginous yeast Y. lipolytica IFP29 (ATCC 20460) was grown during $16 \mathrm{~h}$ in a shake flask containing $100 \mathrm{~mL}$ of YEPD Broth using a shaking incubator at $200 \mathrm{rpm}, 28^{\circ} \mathrm{C}$. The fermentation was then carried out in a $3.6 \mathrm{~L}$ fermenter (Labfors 4 , Infors-HT) stirred with two Rushton Impellers. The oleaginous microorganism was grown in batch mode in $1 \mathrm{~L}$ of an industrial substrate containing hydrolyzed starch diluted to an initial concentration in glucose of $60 \mathrm{~g} /$ L at $28^{\circ} \mathrm{C}$ and adjusted to $\mathrm{pH} 4.5$. After consumption of the glucose, the fed-batch mode was started with a solution of dextrose syrup (Sirodex, Tereos Syral) and a solution of $\mathrm{NH}_{4} \mathrm{OH}$ as nitrogen source. The industrial substrate (by-product from a starch plant) was obtained from Tereos Syral. The hydrolysis of starch to glucose was carried out during $24 \mathrm{~h}$ at $55^{\circ} \mathrm{C}$ and $\mathrm{pH} 4.5$ using a commercial amyloglucosidase (Spirizyme Fuel HS, Novozymes) at a concentration of $120 \mu \mathrm{l} / \mathrm{L}$. After $7 \mathrm{~h}$ of fermentation, the biomass was harvested by centrifugation at $5000 \mathrm{rpm}$ for $15 \mathrm{~min}$ and washed once with demineralized water to remove the residual nutrients. All the fermentation musts used for the extractions contains $9.93 \%$ of dry matter.

\subsection{Conventional lipids extraction methods}

The standard solvent mixture methanol:chloroform approved for extraction of lipids from yeast (Bligh and Dyer, 1959; Folch et al., 1957) was employed to determine and compare the lipid yield of yeast. A quantity of $3 \mathrm{~g}$ of wet yeast biomass was mixed with $10 \mathrm{~mL}$ of solvent mixture of chloroform and methanol $(1: 2$, $\mathrm{v} / \mathrm{v}$ ) and subjected for $30 \mathrm{~min}$ at room temperature with a constant stirring. The mixture was then centrifuged at $5000 \mathrm{rpm}$ for $5 \mathrm{~min}$. The lower phase was recovered and transferred in a vial and conserved in freezer at $-4{ }^{\circ} \mathrm{C}$ for the further analysis. The experiment was performed in triplicate.

\subsection{Intensification of extraction methods}

Various intensified extraction processes (bead milling, microwave, and ultrasound) were compared to conventional maceration. All the extractions were performed with the standard solvent mixture of chloroform and methanol $(1: 2, \mathrm{v} / \mathrm{v})$. After extraction, the biomass was separated from the solvent by centrifugation at $5000 \mathrm{rpm}$ during $5 \mathrm{~min}$, and then the lower phase was recovered, placed in vial and conserved at $-4{ }^{\circ} \mathrm{C}$ until analyses. Each extraction was performed in triplicate to calculate the standard deviation (SD). All these processes were illustrated in Fig. 1.

\subsubsection{Ultrasonic-assisted extraction}

Ultrasonic-assisted extraction was carried out using an ultrasonic device operating at low frequencies $(20 \mathrm{kHz})$ with $1000 \mathrm{~W}$ ultrasonic processor $(1 \mathrm{~kW}$, UIP1000hdT, Hielscher Ultrasonics $\mathrm{GmbH}$, Germany). $10 \mathrm{~g}$ of wet yeast biomass was mixed to $50 \mathrm{~mL}$ of standard solvent mixture of chloroform and methanol $(1: 2, \mathrm{v} /$ $\mathrm{v}$ ) in a double jacket reactor and was subjected to sonication during 30 min with an ultrasonic power of $300 \mathrm{~W}$. Extraction temperature was measured with an external sensor and regulated at $20 \pm 2{ }^{\circ} \mathrm{C}$ using a cooling system (Ministat 125 , Huber, Germany).

\subsubsection{Bead milling}

Extraction by bead milling was performed using ULTRATURRAX $^{\circledR}$ Tube Drive (UTTD, Ika, Germany) operating in a $20 \mathrm{~mL}$ tube with $20 \mathrm{~g}$ of ceramic beads. $3 \mathrm{~g}$ of fresh biomass was mixed with $10 \mathrm{~mL}$ of standard solvent mixture of chloroform and methanol $(1: 2, v / v)$ and submitted in drive tube operating at $4000 \mathrm{rpm}$ during $30 \mathrm{~min}$. After extraction, the beads were filtered before solid/liquid separation by centrifugation.

\subsubsection{Microwave-assisted extraction}

Microwave extraction was carried out using a microwave reactor (1 kW, Ethos 1, Milestone, Italy). A quantity of yeasts ( $10 \mathrm{~g}$ ) was introduced with $50 \mathrm{~mL}$ of standard solvent mixture of chloroform and methanol $(1: 2, v / v)$ in a Teflon reactor and heated until the fixed temperature. Microwave extraction was performed with a constant power of $1000 \mathrm{~W}$ and a temperature of $110^{\circ} \mathrm{C}$, and then intern vapor pressure reaches 20 bars for $30 \mathrm{~min}$. Temperature and pressure were measured monitored during microwave extractions. 
Version définitive du manuscrit publiée dans / Final version of the manuscript published in :

Bioresource Technology (2016), Vol. 211, p. 190-199, DOI: 10.1016/j.biortech.2016.03.040

Journal homepage : www.elsevier.com/locate/biortech
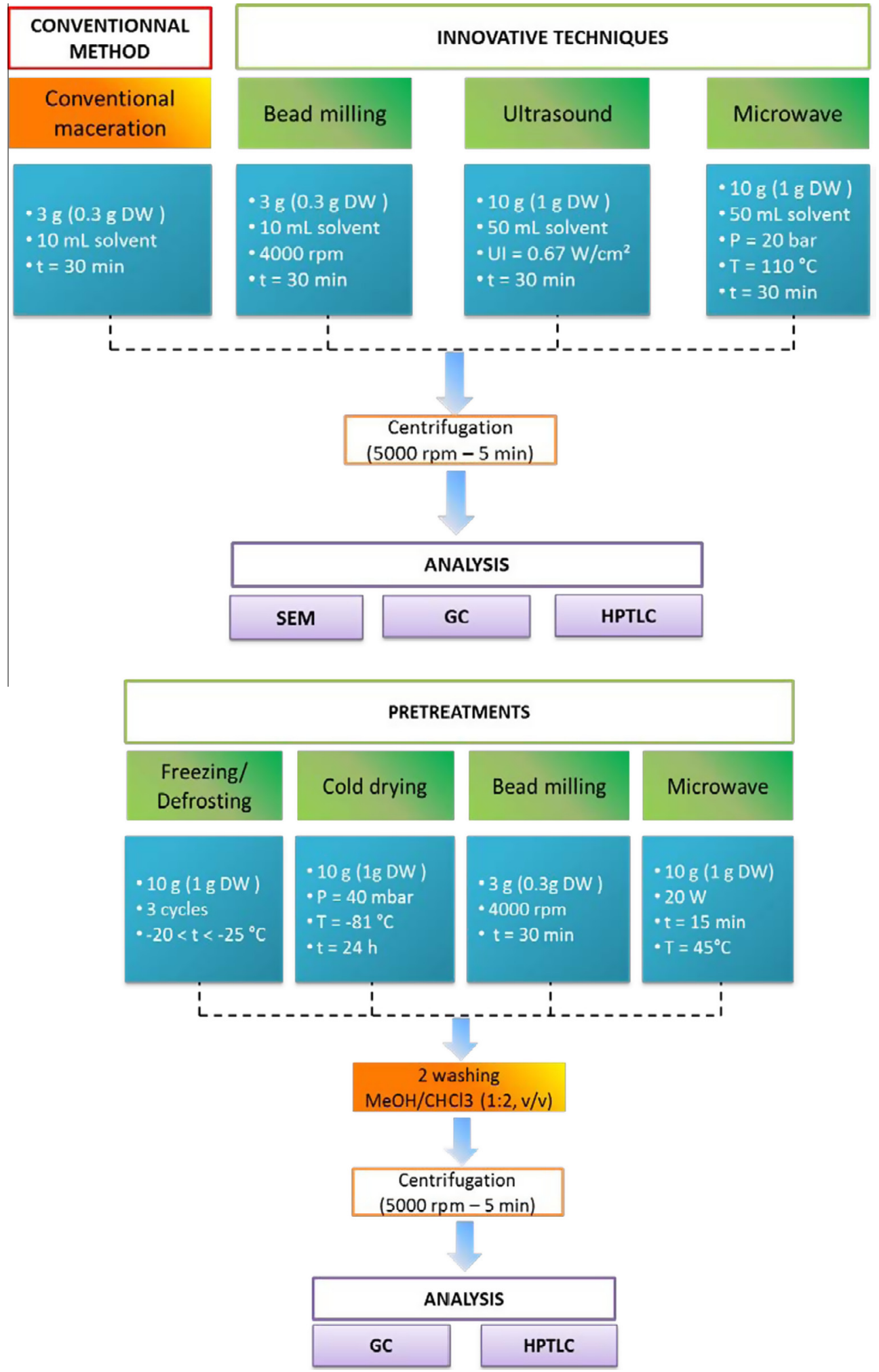

Fig. 1. Global protocol for microbial oils extraction.

\subsection{Pretreatment procedures}

Y. lipolytica yeast was submitted to various pretreatments (cold drying, freezing/defrosting, bead mills, and microwave), then two washing were realized with standard mixture of chloroform:metha- $\operatorname{nol}(1: 2, \mathrm{v} / \mathrm{v})$ at room temperature. Then, the biomass was separated from the solvent by centrifugation at $5000 \mathrm{rpm}$ during $5 \mathrm{~min}$. The lower phase was recovered, placed in vial and conserved at $-4{ }^{\circ} \mathrm{C}$ until further analyses. Each extraction was performed in triplicate in order to calculate the standard deviation (SD). 


\subsubsection{Cold drying under reduced pressure}

Cold drying under reduced pressure was carried out using Cosmos (Cryotec, France). Yeast biomass was placed in the reactor and cooled until a temperature of $-80^{\circ} \mathrm{C}$. At set temperature, samples were submitted to a reduced pressure of -20 mbar during $48 \mathrm{~h}$, until samples own a constant weight. Dried biomass was conserved in freezer until further extraction.

\subsubsection{Freezing/defrosting}

Yeast was frozen at $-20^{\circ} \mathrm{C}$ during $24 \mathrm{~h}$ and then placed on refrigerator at $4^{\circ} \mathrm{C}$ during $12 \mathrm{~h}$ until complete defrosting. These steps were repeated three times before further extraction.

\subsubsection{Bead milling}

Pre-treatment by bead milling was performed using ULTRATURRAX $^{\circledR}$ Tube Drive (UTTD, Ika, Germany) operating in a $20 \mathrm{~mL}$ tube with $20 \mathrm{~g}$ of ceramic beads. $3 \mathrm{~g}$ of fresh biomass was submitted in drive tube operating at $4000 \mathrm{rpm}$ during $30 \mathrm{~min}$.

\subsubsection{Microwave pretreatment}

Microwave pre-treatment was carried out using a Milestone microwave laboratory oven (Neos, Milestone, Italy). It is a multimode microwave reactor $2.45 \mathrm{GHz}$ with a maximum delivered power of $900 \mathrm{~W}$ variable in $10 \mathrm{~W}$ increments. Temperature was monitored by a fluoroptic and infrared (IR) sensors. A quantity of yeasts $(10 \mathrm{~g})$ was introduced in a Teflon reactor and heated until the fixed temperature. Microwave extraction was performed during 15 min with a constant power of $20 \mathrm{~W}$ and a temperature of $45^{\circ} \mathrm{C}$ to avoid burning.

\subsection{Lipid analysis composition}

\subsubsection{Quantitative and qualitative analysis of lipids classes}

Lipid classes in microbial oil extracted were determined by high performance thin-layer chromatography (HPTLC), using a two different developments chromatography to separate polar and neutral classes. Lipids were quantified by a CAMAG 3 TLC scanning densitometer (CAMAG, Muttenz, Switzerland) with identification of the classes against known polar and neutral lipid standards. Lipid extracts were loaded as a spot onto $20 \times 10 \mathrm{~cm}$ silica gel 60 F254 HPTLC plates (Merck KGaA, Darmstadt, Germany) using an ATS 5 automatic TLC sampler (CAMAG, Switzerland). The HPTLC silica gel plates were developed with mixture of solvents in an ADC2 automatic developing chamber (CAMAG, Switzerland). The first eluent to separate polar lipids was a mixture of methyl acet ate/isopropanol/chloroform/methanol/ $\mathrm{KCl}(0.25 \%$ solution) in a ratio of $25: 25: 25: 10: 9 \mathrm{v} / \mathrm{v} / \mathrm{v} / \mathrm{v} / \mathrm{v}$ running to a height of $7 \mathrm{~cm}$ from the origin. And the second eluent was a mixture of n-hexane/ diethyl ether/glacial acetic acid in a ratio of 70:30:2 v/v/v to a height of $7 \mathrm{~cm}$ from the origin. After dried, the plate was dipped for $6 \mathrm{~s}$ in a reagent $(10 \mathrm{mg}$ of primuline, $160 \mathrm{~mL}$ of acetone, $40 \mathrm{~mL}$ of water), then scanned using a TLC Scanner 3 with WinCATs software (CAMAG). Lipid classes of each microbial oil were identified and quantified against those of corresponding lipid standards.

\subsubsection{Preparation of fatty acids methyl ester (FAMEs)}

FAMEs were prepared from the lipid extract using acidcatalyzed transmethylation. $1 \mathrm{~mL}$ of methanolic sulfuric acid (5\%) solution was added to a specific amount of extracted microbial oil. Triheptadecanoin (C17:0 TAG) was used as internal standard. The mixture was then heated during $90 \mathrm{~min}$ at $85^{\circ} \mathrm{C}$. After, the flask was removed from heat and $1.5 \mathrm{~mL}$ of sodium chloride $(0.9 \% \mathrm{wt} / \mathrm{v})$ solution and $1 \mathrm{~mL}$ of $n$-hexane were added. The flask was closed and shook vigorously during $30 \mathrm{~s}$. A small amount of the organic layer was recovered and transferred to a vial before being injected directly in a gas chromatograph for analysis.

\subsubsection{FAMEs analysis}

Fatty acids methyl esters were separated, identified and quantified by gas chromatography coupled with flame ionization detector (GC-FID). The instrument Agilent (Kyoto, Japan) was equipped with a BD-EN14103 capillary column $30 \mathrm{~m} \times 320 \mu \mathrm{m} \times 0.25 \mu \mathrm{m}$ (Agilent) and the velocity of the carrier gas (He) was at $33 \mathrm{~cm} / \mathrm{s}$. Injection of $2 \mu \mathrm{l}$ of the various samples were carried out with a split mode (split ratio $1: 20$ ) and the injector temperature was set at $250{ }^{\circ} \mathrm{C}$. Oven temperature was initially $50^{\circ} \mathrm{C}$ for $1 \mathrm{~min}$ and then progressed at a rate of $20^{\circ} \mathrm{C} / \mathrm{min}$ from $50^{\circ} \mathrm{C}$ to $180^{\circ} \mathrm{C}$ and then increased from $180^{\circ} \mathrm{C}$ to $220^{\circ} \mathrm{C}$ at a rate of $2^{\circ} \mathrm{C} / \mathrm{min}$. The temperature was then held at $230^{\circ} \mathrm{C}$ over $10 \mathrm{~min}$. FAMEs were identified by retention time and comparison with purified FAME standards (Sigma Co., USA).

\subsection{Scanning electron microscopy}

Y. lipolytica yeasts were observed by electronic microscopy using FEI/Philips XL30 at initial state and after treatments by microwave, bead milling, ultrasound, freezing/defrosting, and cold drying, in order to evaluate the impact of each treatment on the microstructure. The accelerating voltage used is $10 \mathrm{kV}$. After being carefully collected, the samples were put in glutaraldehyde $2.5 \%$ $(\mathrm{v} / \mathrm{v})$ in cacodylate sodium buffer in order to fix the structures and were kept $1 \mathrm{~h}$ in room temperature before being post-fixated with osmium tetroxide (diluted to $1 \%(\mathrm{v} / \mathrm{v})$ ). Samples were then rinsed in water baths followed by dehydration using increasing ethanol baths (30\%, 50\%, 70\%, 90\%, and 100\%). The last step of the dehydration process was a hexamethyl disilazane bath until full evaporation and the samples were then gold plated before being observed by scanning electron microscopy.

\section{Results and discussion}

\subsection{Comparison of extraction and pretreatment processes in terms of extraction yield}

Extraction obtained by conventional maceration using solvent mixture of Bligh and Dyer method chloroform:methanol $(1: 2, \mathrm{v} /$ v) was compared to bead milling, ultrasound and microwaveassisted extraction and are presented in Fig. 2. Maceration with conventional solvent of chloroform:methanol $(1: 2, \mathrm{v} / \mathrm{v})$ is the most cited reference method in the literature for extraction of lipids from biological materials (Burja et al., 2007). The extraction yield was quantified using GC/MS and HPTLC. Lipid yield from Y. lipolytica obtained by this conventional method was $6.23 \pm 0.51 \mathrm{~g} / 100 \mathrm{~g}$ of dry weight (dw). Regarding the alternative methods of extraction (bead milling, ultrasound, and microwave), higher extraction yields were obtained within the same time ( $30 \mathrm{~min}$ ) than conventional maceration. Indeed, microorganisms mainly yeast strain have a rigid cell wall compared to other biological sample; in consequence it is difficult to obtain a complete extraction process with a simple maceration (Zhang et al., 1999). Mechanical treatment using bead milling appears to be the most efficient technique, lipids yield of extraction was more than two times superior for the same extraction time compared to the reference method $(13.16 \pm 0.68 \mathrm{~g} / 100 \mathrm{~g}$ of $\mathrm{dw})$. For ultrasound-assisted extraction, temperature was maintained at $25^{\circ} \mathrm{C}$ for $30 \mathrm{~min}$ with an ultrasonic power of $300 \mathrm{~W}$. The lipid recovery was $8.10 \pm 0.24 \mathrm{~g} / 100 \mathrm{~g}$ of dw, thus ultrasonication increases lipid recovery. While microwaveassisted extraction was performed with more drastic conditions $\left(P=20\right.$ bar and $T=110^{\circ} \mathrm{C}$ ), lipid recovery was less than ultrasound-assisted extraction and bead milling extraction but remains slightly higher than conventional maceration $(7.13 \pm 0.45 \mathrm{~g} / 100 \mathrm{~g}$ of $\mathrm{dw})$. This difference can be due to a 
Version définitive du manuscrit publiée dans / Final version of the manuscript published in :

Bioresource Technology (2016), Vol. 211, p. 190-199, DOI: 10.1016/j.biortech.2016.03.040

Journal homepage : www.elsevier.com/locate/biortech

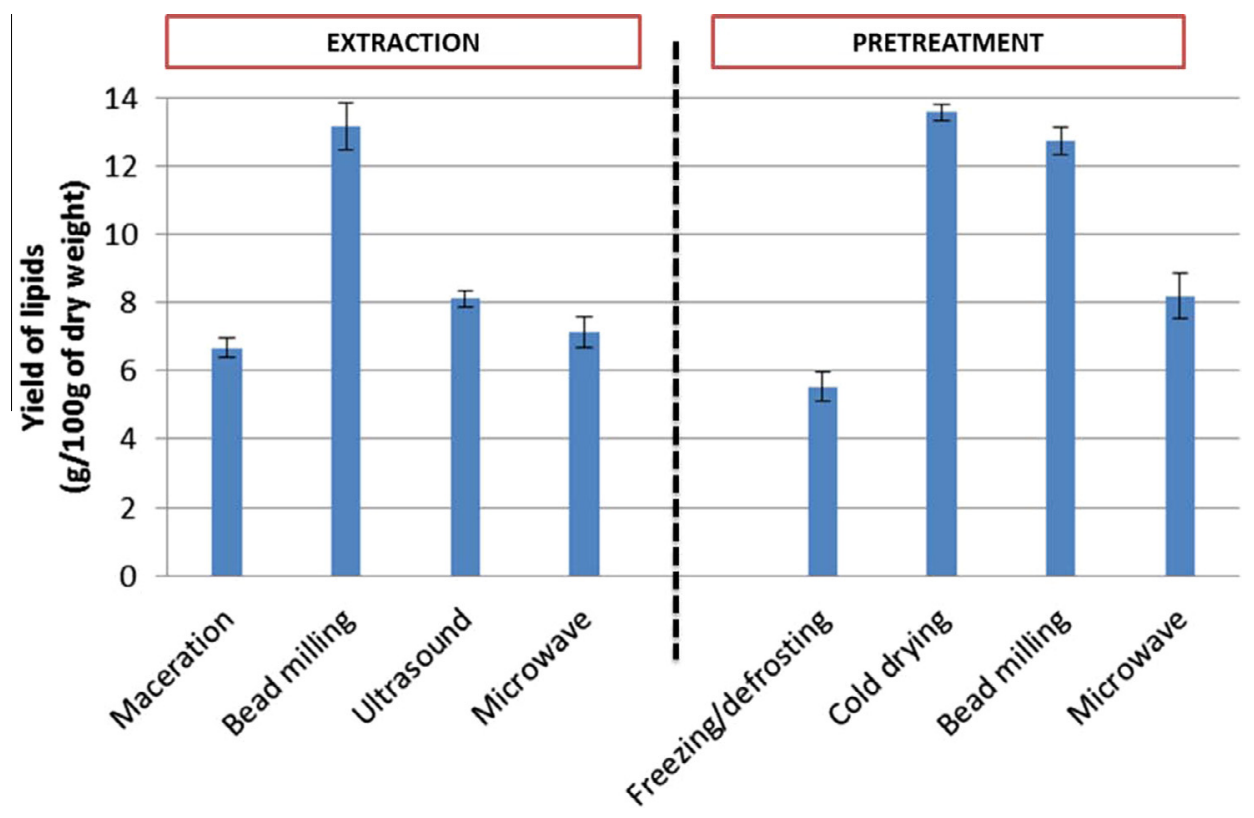

Fig. 2. Effect of extraction and pretreatment processes on lipids extraction yield.

degradation of lipids with the drastic conditions. It was observed that various processes such as bead milling, ultrasound and microwave can easily intensified the classical maceration using solvent mixture of Bligh and Dyer. The question, which could be asked, is: Is it necessary to change an entire industry installation to replace it by an intensified process or only adding a pretreatment step before conventional extraction could be sufficient for a complete recovery of lipids? For that different pretreatments such as freezing/defrosting, cold drying, bead milling, and microwave were tested followed by two leaching with B \& D solvent mixture and compared to a conventional maceration (Table 1). Fig. 2 shown that three cycles of freezing/defrosting was not efficient as pretreatment for lipids extraction from Y. lipolytica, the extraction yield achieved is lesser than a conventional maceration $(5.53 \pm 0.43 \mathrm{~g} / 100 \mathrm{~g}$ of $\mathrm{dw})$. A cold drying under pressure of yeast prior extraction allowed for disrupting the cells walls and to reach the maximum yield of lipids obtained by the various pretreatments, with a yield about
$13.56 \pm 0.24 \mathrm{~g} / 100 \mathrm{~g}$ of $\mathrm{dw}$. A pretreatment of $30 \mathrm{~min}$ by bed milling of yeast appears to be efficient; the recovery of lipid was around two times higher than a classical maceration $(12.73 \pm 0.41 \mathrm{~g} / 100 \mathrm{~g}$ of $\mathrm{dw}$ ). For microwave pretreatment of 15 min with a power of 20 Watt permits to increase the lipids recovery to compare to maceration, $8.18 \pm 0.67 \mathrm{~g} / 100 \mathrm{~g}$ of $\mathrm{dw}$.

A general observation of the results shows that a preliminary step as cell disruption (to break and/or open cell wall) improves extraction efficiency, as the various intensified extraction processes. Finally the choice of the method (pretreatment or intensified processes) will depend on the target. Pretreatments adds one more step for the process which could generate enhancement in global processing time and energy, in the other hand, intensified extraction process such as bead milling, ultrasound or microwave will reduce extraction time and energy but will require high initial investment to change the initial conventional extraction process.

Table 1

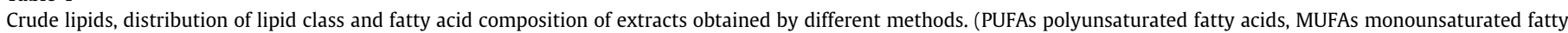
acids, SFAs saturated fatty acids).

\begin{tabular}{|c|c|c|c|c|c|c|c|c|}
\hline & Conventional maceration & Bead milling & Ultrasound & Microwave & Freezing/defrosting & Cold drying & Bead milling & Microwave \\
\hline Lipid yield (\%) & $6.23 \pm 0.51$ & $13.16 \pm 0.68$ & $8.10 \pm 0.24$ & $7.13 \pm 0.45$ & $5.53 \pm 0.43$ & $13.56 \pm 0.24$ & $12.73 \pm 0.41$ & $8.18 \pm 0.67$ \\
\hline \multicolumn{9}{|c|}{ Lipid classes composition } \\
\hline DAG & $15.16 \pm 0.01$ & $11.61 \pm 0.06$ & - & - & 12.79 & 15.43 & 11.96 & - \\
\hline TAG & $71.60 \pm 0.18$ & $82.69 \pm 0.15$ & $83.28 \pm 0.18$ & $75.76 \pm 0.13$ & $65.65 \pm 0.08$ & $76.97 \pm 0.11$ & $80.22 \pm 0.14$ & $75.11 \pm 0.07$ \\
\hline FFA & $13.24 \pm 0.05$ & $5.70 \pm 0.02$ & $16.72 \pm 0.07$ & $24.24 \pm 0.05$ & $21.56 \pm 0.03$ & $7.60 \pm 0.02$ & $7.82 \pm 0.01$ & $24.84 \pm 0.03$ \\
\hline \multicolumn{9}{|c|}{ Fatty acids composition } \\
\hline \multicolumn{9}{|c|}{ Saturated } \\
\hline C16 & $12.45 \pm 0.04$ & $10.55 \pm 0.05$ & $18.72 \pm 0.05$ & $14.39 \pm 0.03$ & $13.33 \pm 0.03$ & $11.97 \pm 0.03$ & $13.93 \pm 0.02$ & $14.85 \pm 0.07$ \\
\hline $\mathrm{C} 18$ & $3.24 \pm 0.01$ & $4.43 \pm 0.02$ & $2.42 \pm 0.01$ & $2.77 \pm 0.05$ & $2.71 \pm 0.01$ & $3.78 \pm 0.01$ & $2.94 \pm 0.01$ & $2.81 \pm 0.01$ \\
\hline \multicolumn{9}{|c|}{ Mono-unsaturated } \\
\hline C16:1 n9 & $6.18 \pm 0.02$ & $5.42 \pm 0.01$ & $9.50 \pm 0.08$ & $6.91 \pm 0.01$ & $6.49 \pm 0,02$ & $6.42 \pm 0.02$ & $7.21 \pm 0.05$ & $7.45 \pm 0.02$ \\
\hline C18:1 n9 & $46.38 \pm 0.08$ & $47.75 \pm 0.07$ & $41.08 \pm 0.06$ & $43.75 \pm 0.05$ & $44.61 \pm 0.09$ & $45.77 \pm 0.08$ & $44.57 \pm 0.11$ & $42.31 \pm 0.09$ \\
\hline \multicolumn{9}{|c|}{ Poly-unsaturated } \\
\hline C18:2n6 & $30.58 \pm 0.05$ & $30.20 \pm 0.06$ & $27.18 \pm 0.04$ & $30.61 \pm 0.04$ & $31.11 \pm 0.07$ & $34.59 \pm 0.10$ & $30.45 \pm 0.04$ & $31.79 \pm 0.06$ \\
\hline $\mathrm{C} 18: 3 \mathrm{n} 3$ & $0.70 \pm 0.01$ & $0.67 \pm 0.02$ & $0.37 \pm 0.02$ & $0.67 \pm 0.02$ & $0.67 \pm 0.02$ & $0.82 \pm 0.03$ & $0.55 \pm 0.03$ & $0.29 \pm 0.01$ \\
\hline Total SFAs & $15.69 \pm 0.05$ & $14.98 \pm 0.07$ & $21.15 \pm 0.06$ & $17.15 \pm 0.08$ & $16.04 \pm 0.04$ & $15.75 \pm 0.04$ & $16.88 \pm 0.03$ & $17.66 \pm 0.08$ \\
\hline Total MUFAs & $52.56 \pm 0.10$ & $53.16 \pm 0.08$ & $50.58 \pm 0.14$ & $50.66 \pm 0.06$ & $51.10 \pm 0.11$ & $52,19 \pm 0.10$ & $51.79 \pm 0.16$ & $49.76 \pm 0.11$ \\
\hline Total PUFAs & $31.28 \pm 0.06$ & $30.87 \pm 0.08$ & $27.55 \pm 0.06$ & $31.28 \pm 0.06$ & $31.78 \pm 0.09$ & $35.41 \pm 0.13$ & $31.00 \pm 0.07$ & $32.07 \pm 0.07$ \\
\hline
\end{tabular}


Version définitive du manuscrit publiée dans / Final version of the manuscript published in :

Bioresource Technology (2016), Vol. 211, p. 190-199, DOI: 10.1016/j.biortech.2016.03.040

Journal homepage : www.elsevier.com/locate/biortech

\subsection{Processing impact on lipid class composition}

Microbial oils are classified in two categories according to their polarities: neutral lipids and polar lipids. Microbial oils tend to accumulate neutral lipids, include monoacylglycerol (MAG), diacylglycerol (DAG), triacylglycerol (TAG), free fatty acids (FFA), and alkyl chain. Lipid droplets are localized in the cytoplasm and in cells walls as energy storage form of carbon and energy. Neutral lipids of the extracted microbial oils were separated and quantified using high-performance thin-layer chromatography (HP-TLC). For all microbial oil extracted with various processes without pretreatment (maceration, bead milling, ultrasound, and microwave) and with pretreatments (freezing/defrosting, cold drying, bead milling, and microwave), the distribution of the different lipid classes was obtained by the external calibration. To quantify the percentage of lipid classes, four standards were used in a mixture of MAG, DAG, TAD, and FFA (C18) and deposited on the HP-TLC plate. As shown in Fig. 4, monoglycerides (MAG) were not found in all the extracts. Triglycerides (TAG) are the major components of all the microbial oils extracted, with a percentage between $71 \%$ and $83 \%$ of total lipids according to the extraction method (Fig. 3). For ultrasound and microwave extraction and pretreatment, the composition of oils is almost similar and composed of TAG and a higher amount of FFA than other extracts. Ultrasound and microwave treatments induce a degradation of DAG into FFA. Generally, lipid degradation emerges from hydrolysis or oxidation, which can occur by autooxidation, photo-oxidation, or enzymatic-oxidation. Fatty acids composition, oxygen, heat, photosensibilisation, and presence of minor compounds such as metals, phospholipids, FFA, MAG and TAG are the main factors responsible of chemical reactions in oil (Pingret et al., 2012a). Critical temperature and pressure conditions generated locally by ultrasound, as well as the loss of metal due to the titanium horn may induce the formation of radicals, then the double bonds of MAG are degraded by oxidation and appears to be transformed in FFA (Das et al., 2013). Extraction by microwave requires high temperature, and the thermal treatment combined to the water contained in wet yeast provokes a slight transformation of DAG in FFA due to oxidation and hydrolysis of microbial oil, unlike conventional maceration and bead milling, which are cold extraction methods.

\subsection{Processing impact on fatty acids composition}

The fatty acids composition of lipids extracted from Y. lipolytica using four intensified extraction methods (maceration, bead milling, ultrasound, and microwave) and four pretreatments methods (freezing/defrosting, cold drying, bead milling, and microwave) are presented in Table 1. The classes and their relative proportion of FAMEs composition in all microbial oils was determined by GCFID analysis. As shown in Fig. 4, for all the extraction methods, the FAMEs compositions are almost equivalent excepted for ultrasound assisted extraction. In that case, palmitic acid (C16) was found in higher proportion (18\%) than other methods (less than $14 \%)$. The sum percentages of saturated, poly- and monosaturated fatty acids were slight different of tables dealing found in literature (Wang et al., 2011) can be due to the culture conditions, the change of strain, etc. The proportion of SFAs, PUFAs, or MUFAs are almost similar for all the treatments employed, as a conclusion all the innovative treatments used in this study have not been affected the proportion of saturated, poly- and monosaturated fatty acids. The main fatty acids were oleic (C18:1n9) acid (comprised between $41 \%$ and $48 \%$ ) and linoleic (C18:2n6) acid (between $27 \%$ and $32 \%$ ). These two fatty acids represent more than $70 \%$ of the total fatty acid composition of all the extracts. Linolenic acid (C18:3n3) was found in trace levels $(<0.7 \%)$.

\subsection{Comparison of bead milling extraction and conventional maceration kinetics}

To understand, why bead milling extraction is more efficient than conventional maceration, a kinetic comparative study was performed between bead milling extraction (BME) and conventional maceration (CVM) in the conditions described in Section 2.3.2 (the same conditions except grinding). As shown in Fig. 5a, BME extraction permits to greatly improve the lipid recovery by more than $50 \%$ ( 6.82 and $13.81 \mathrm{~g} / 100 \mathrm{~g}$ of $\mathrm{dw}$ for CVM and $\mathrm{MC}$ as a maximum of lipids extraction, respectively). The kinetic of extraction was clearly improved, which could be explained by the grinding phenomena give rise to the rotation at $4000 \mathrm{rpm}$ of beads. First step consists in a rapid increase of lipids yield, corresponding to the solubilization of lipids in the medium. The second

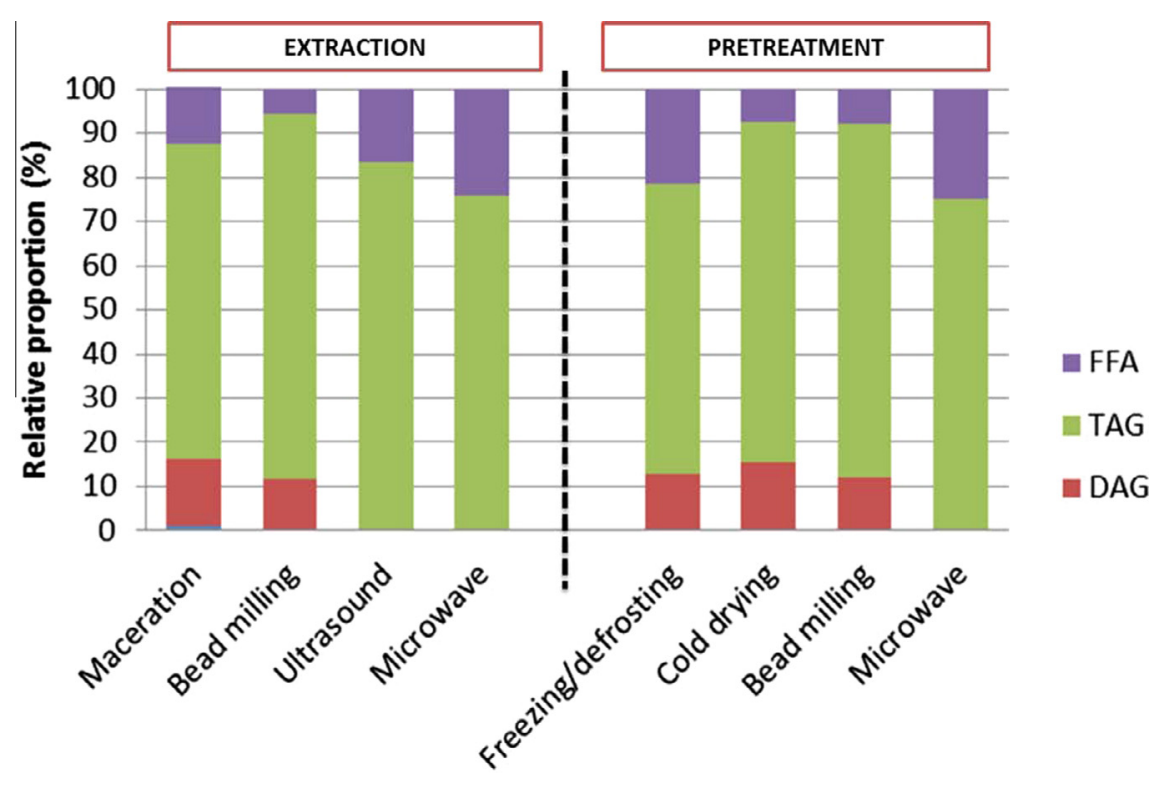

Fig. 3. Distribution of lipid classes by HP-TLC according to various treatments. 


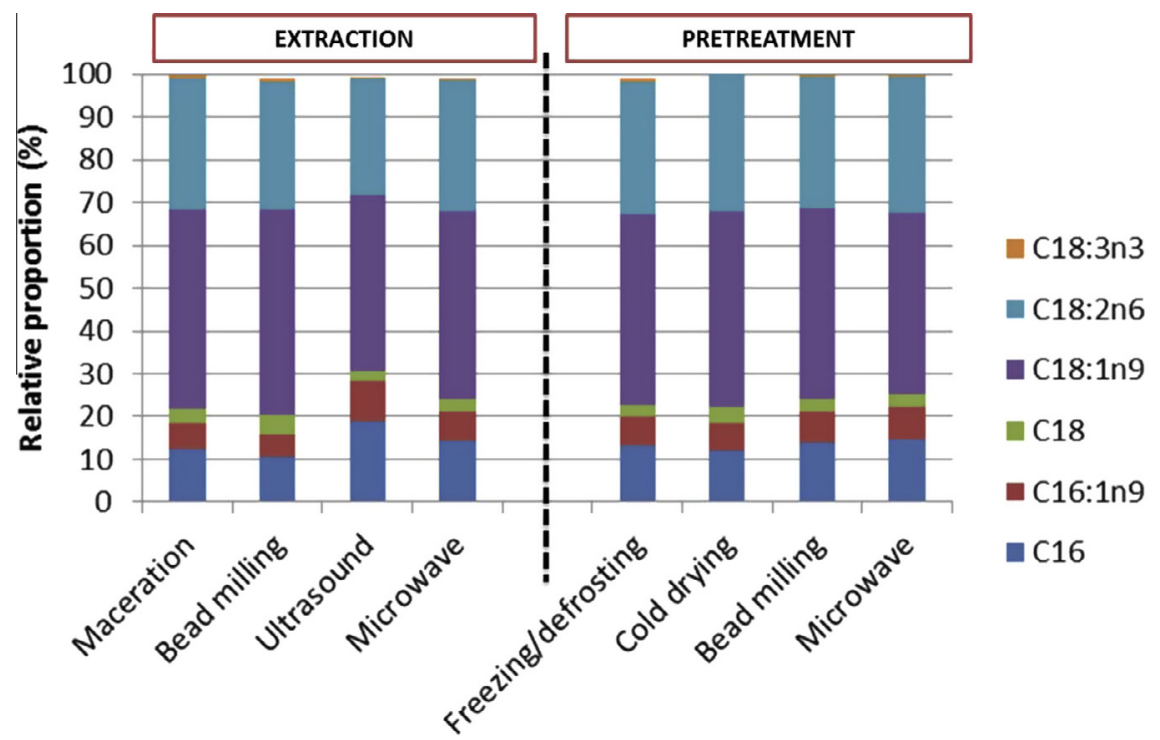

Fig. 4. Distribution of FAMEs classes by GC according to various treatments.

step is almost a horizontal line, which marks the end of the extraction process; this step corresponds to the diffusion of lipids in the medium.

In integrated form, the kinetics were fitted to first-order rate equation derived from a quasi-steady model of extraction (Spiro and Selwood, 1984), and can be described by Eq. (1).

$\left(\ln \frac{y_{\infty}}{y_{\infty}-y(t)}\right)=k_{i}+a$

where $y_{\infty}$ is the extraction yield at the end of process, $y(t)$ the yield of extraction at time $t, y$ is the final extraction yield, $k_{i}$ a first-order rate constant, and " $a$ " the semi empirical intercept.

When $\left(\ln \frac{y_{\infty}}{y_{\infty}-y(t)}\right)$ is plotted against time, the points fall on two intersecting straight lines, the first with relative steep slope and the second with a relatively shallow one.

For the two techniques, extraction of lipids occurred in two distinct kinetic steps (0-10 min and $10-45 \mathrm{~min})$ as testified by the rupture of the slope in the linear plots drawn in Fig. 5b. During the first step, the first-order kinetic rate constant was higher for BME than CVM (0.1461 and $0.2249 \mathrm{~min}^{-1}$ for BME and CVM, respectively). Whereas during the second step, the extraction rates were almost similar (0.0525 and $0.0479 \mathrm{~min}^{-1}$ for BME and CVM, respectively), with $R^{2}>0.98$ for all the experiments. From this observation, the difference in term of performance between the conventional and intensified technique is not a limitation of time. The diffusion of solute in the solvent generally constitutes the limitation step in the processus of extraction. The diffusion coefficient applied in solid/liquid extraction can be described by second Fick law's (Herodež et al., 2003):

$\frac{\partial y}{\partial t}=-D_{\text {eff }} \frac{\partial y}{\partial x}$

As shown in Table 2, the coefficient of effective diffusion $\left(D_{\text {eff }}\right)$ was almost two times higher during extraction by bead milling compared to conventional maceration (36.5 and $23.7 \times 10^{-16} \mathrm{~m}^{2}$ ) $\mathrm{s}$ for BME and CVM, respectively). Thus the diffusion is clearly limited during conventional maceration, due to the strong cells wall of yeast. An addition of bead milling during the extraction permits an efficient breaking of cells wall and allowed to reach a total extraction of lipids. Extraction by bead milling allowed accelerating the dissolution and diffusion speed of target compounds between the matrix and the solvent. These statements have been reported previously by Xie et al. (2013) in the case of flavonoids extraction from bamboo leaves.

\subsection{Comprehension of mechanism}

Extraction is one the most important step that requires $70 \%$ of the total processing time, for a conventional solvent extraction (Pingret et al., 2012b). Knowledge of the presence of target molecules in the matrix, solvent selection, choice of the technique is primordial, because generally the limitation step is the diffusion of solvent into the raw material.

Fig. 6 shown the initial structure of $Y$. lipolytica strain (schema and image by SEM and the mechanisms (1) of each process employed and the SEM image associated (2). At initial state $Y$. lipolytica is of oval form of around $2 \mu \mathrm{m}$ of length, possessing a rigid cell wall. During conventional maceration, the solid solute, in our case lipid components are separated from a mixture of insoluble solids by dissolving it in a liquid phase, such as the matter transfer into liquid phase. SEM image of $Y$. lipolytica after conventional maceration does not show significant difference compared to the initial strain (Fig. 6). This observation is in agreement with the results of extraction yield obtained by conventional maceration, which are lesser than other extraction techniques. The natural structure of $Y$. lipolytica and the resistance of cell wall clearly limit the intracellular transfer of lipids. Mechanical extraction using bead milling is partially filled with the yeast and the mixture solvent of methanol:chloroform, together with grinding media such as ceramic balls. The high centrifugal force acting on the balls by rotation at high speed $(4000 \mathrm{rpm})$ provokes the high energy due to the shock of balls between her and on yeast. This phenomenon is confirmed by SEM image of yeast after treatment by bead milling, where many cellular debris is clearly visible around the cell, that induces the mechanical extraction by bead milling are efficient for cell disruption, as demonstrated by Montalescot et al. (2015) in the case of microalgae. Two different treatments were tested by microwave, first one was direct solvent extraction and the second one was a pretreatment of yeast under irradiation. Microwave is a non-contact source, which is the particularity to instantly heat and preferentially polar molecules, especially water. Under microwave irradiation the yeast cells are immediately stimulated and subjected to high stresses, which cause disintegration of 
Version définitive du manuscrit publiée dans / Final version of the manuscript published in :

Bioresource Technology (2016), Vol. 211, p. 190-199, DOI: 10.1016/j.biortech.2016.03.040

Journal homepage : www.elsevier.com/locate/biortech

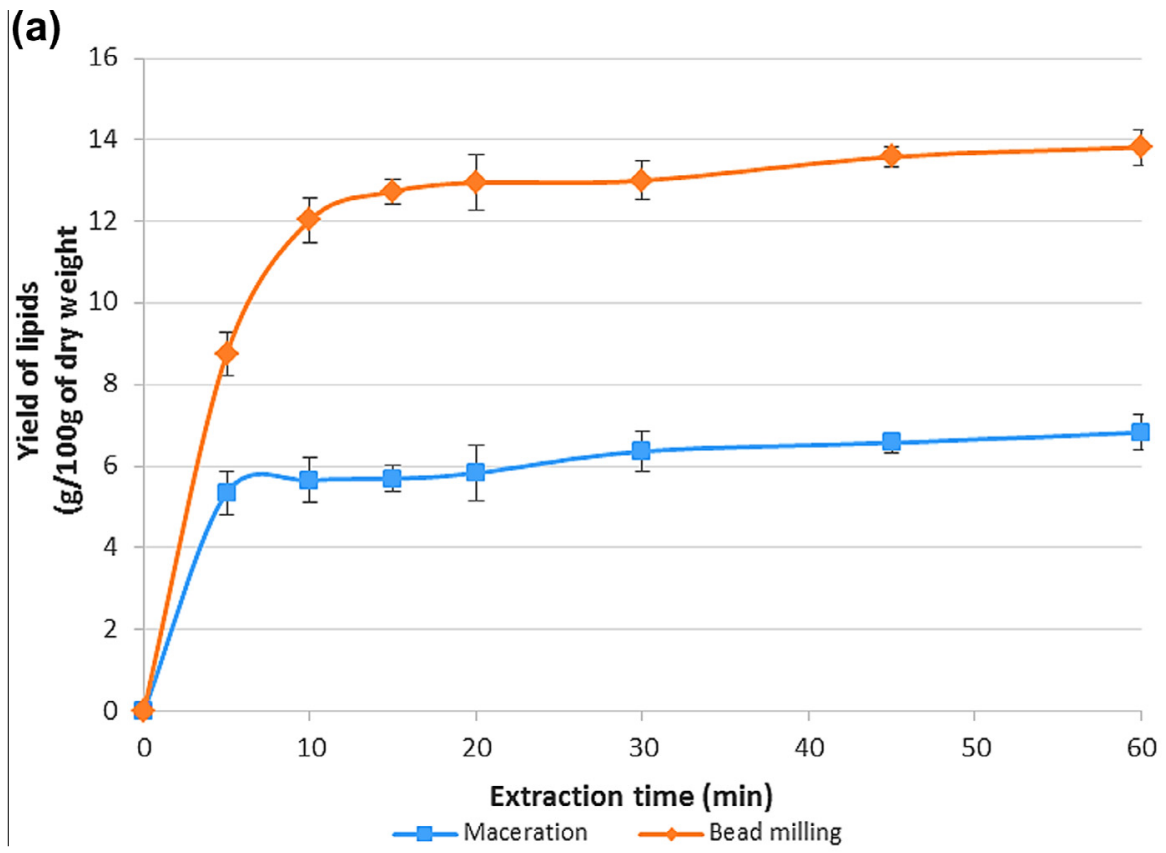

(b)

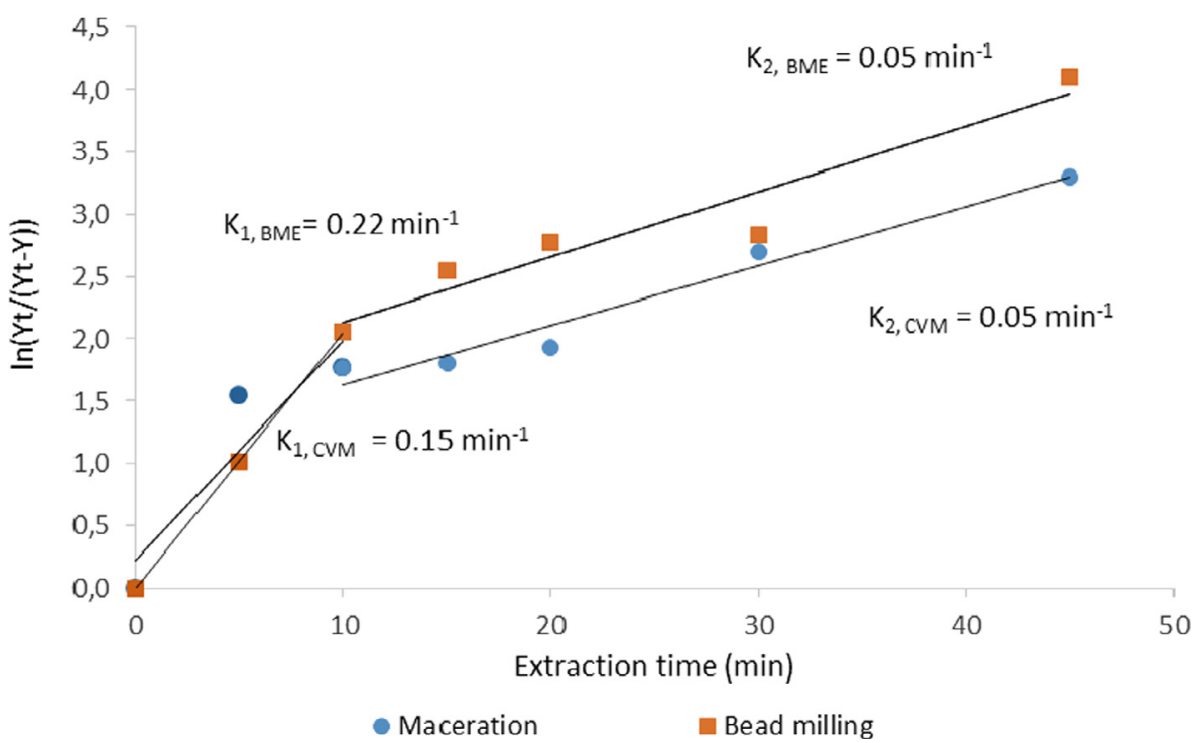

Fig. 5. Kinetics (a) and modelization of extraction kinetics (b) of lipids by bead milling extraction (BME) compared to conventional maceration (CV).

Table 2

Results of extraction kinetic modeling.

\begin{tabular}{lll}
\hline & Conventional maceration & Bead milling \\
\hline$K_{1}\left(\mathrm{~min}^{-1}\right)$ & 0.15 & 0.22 \\
$K_{2}\left(\mathrm{~min}^{-1}\right)$ & 0.05 & 0.05 \\
$D_{1}\left(\mathrm{~m}^{2} / \mathrm{s}\right)$ & $2.37 E-15$ & $3.65 E-15$ \\
$D_{2}\left(\mathrm{~m}^{2} / \mathrm{s}\right)$ & $7.77 E-16$ & $8.51 E-16$ \\
$D_{1}{ }^{*} 10^{-16}\left(\mathrm{~m}^{2} / \mathrm{s}\right)$ & 23.71 & 36.52 \\
$D_{2}{ }^{*} 10^{-16}\left(\mathrm{~m}^{2} / \mathrm{s}\right)$ & 7.77 & 8.51 \\
$R^{2}$ & 0.98 & 0.99 \\
\hline
\end{tabular}

cells and promoting the release of the molecules of interest. On Fig. 6, the two SEM images after microwave treatment or extraction appear to be different. For microwave extraction cells appear totally exhausted while after a microwave pretreatment does not show variation on the cell but some debris are visible into the medium. Few authors are demonstrated that microwave technology provide the same extraction efficiency as compared to conventional extraction but with an important reduction of extraction time for oleaginous Rhodotorula glutinis (Chuck et al., 2014), and for Saccharomyces cerevisiae yeasts (Khoomrung et al., 2013).

In the case of microorganisms such as yeast (Fig. 6), the ultrasound cavitation bubble generated close to the material surface collapses during a compression cycle and a micro-jet directed toward the surface is created. The high pressure and temperature involved destroying of the cell walls of microorganisms and liberation of lipids into the medium. On SEM image of yeast after ultrasound-assisted extraction, cells are completely drained and exhausted. Ultrasound is one of the most efficient techniques for lipid recovery from $Y$. lipolytica, this result are in agreement with Zhang et al. (2014). On SEM image after thermal treatment by cold drying under pressure, cells appear totally burst. This result is in 
Version définitive du manuscrit publiée dans / Final version of the manuscript published in :

Bioresource Technology (2016), Vol. 211, p. 190-199, DOI: 10.1016/j.biortech.2016.03.040

Journal homepage : www.elsevier.com/locate/biortech

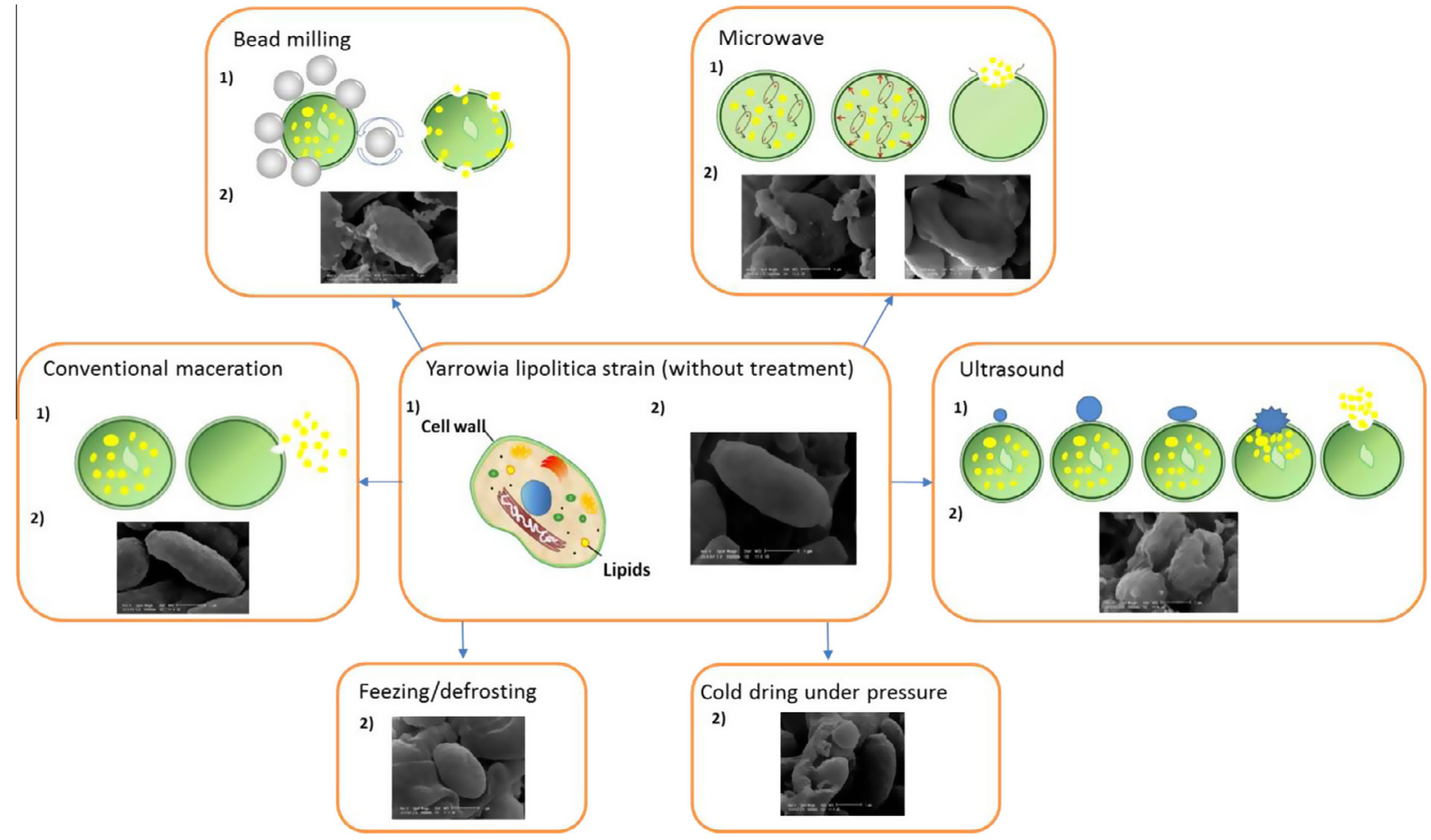

Fig. 6. Effect of extraction processes and pretreatment on Y. lipolytica structure.

Table 3

Energy consumption and carbon emissions of the different extraction processes and pretreatments.

\begin{tabular}{|c|c|c|c|c|}
\hline & & $\begin{array}{l}\text { Experimental conditions } \\
\text { (temperature-extraction conditions) }\end{array}$ & $\begin{array}{l}\text { Energy consumption } \\
\text { (kWh/kg microbial oil extracted) }\end{array}$ & $\begin{array}{l}\text { Carbon emission } \\
(\mathrm{kg} \mathrm{CO} / 2 / \mathrm{kg} \text { microbial oil extracted })\end{array}$ \\
\hline \multirow[t]{4}{*}{ Extraction processes } & Maceration & $20{ }^{\circ} \mathrm{C}$ to $30 \mathrm{~min}$ & 175 & 156 \\
\hline & Bead milling & $20{ }^{\circ} \mathrm{C}$ to $30 \mathrm{~min}$ & 32 & 28 \\
\hline & Ultrasound & $20^{\circ} \mathrm{C}$ to $30 \mathrm{~min}$ & 51 & 45 \\
\hline & Microwave & $110^{\circ} \mathrm{C}$ to $30 \mathrm{~min}$ & 298 & 265 \\
\hline \multirow[t]{4}{*}{ Pretreatments } & Freezing/defrosting & $\begin{array}{l}-20^{\circ} \mathrm{C} \text { to } 24 \mathrm{~h} \\
4{ }^{\circ} \mathrm{C} \text { to } 12 \mathrm{~h}\end{array}$ & 1216 & 1083 \\
\hline & Cold drying & $-80^{\circ} \mathrm{C}$ to $48 \mathrm{~h}$ & 2087 & 1859 \\
\hline & Bead milling & $20{ }^{\circ} \mathrm{C}$ to $30 \mathrm{~min}$ & 33 & 29 \\
\hline & Microwave & $45^{\circ} \mathrm{C}$ to $15 \mathrm{~min}$ & 54 & 48 \\
\hline
\end{tabular}

agreement with the extraction yield of recovery lipid by this pretreatment technique. SEM image by cycles of freezing/defrosting does not show any significant degradation of cells.

\subsection{Energy consumption and environmental impact}

Table 3 indicated the measures of energy consumption and environmental impact per each processes. According to extraction times, it appears clearly that cold drying pretreatment is the mostenergy-consuming technique $(2087 \mathrm{kWh} / \mathrm{kg}$ of microbial oil extracted) and consequently the treatment with the highest carbon emissions associated ( $1859 \mathrm{~kg} \mathrm{CO} / 2 / \mathrm{kg}$ of microbial oil extracted). It is mainly due to the long processing to time $(48 \mathrm{~h})$ and the level of vacuum applied. Bead milling extraction and pretreatment present the lowest values compared to freezing/defrosting, microwave, ultrasound, and conventional maceration. Bead milling extraction resulted in an energy consumption of $32 \mathrm{kWh} / \mathrm{kg}$ of microbial oil extracted and $28 \mathrm{~kg} \mathrm{CO}_{2} / \mathrm{kg}$ of microbial oil extracted. Ultrasound and microwave also appears to reduce the energy-consuming compared to conventional maceration with few differences between microwave extraction and pretreatment. This difference is due to the drastic conditions of temperature applied during extraction compared to a simple pretreatment by microwave. Calculation of environmental impact was performed according to the literature provided by the French Nuclear Energy Society (http://www.sfen. org/fr/societe/developpement/edf.htm): to obtain $1 \mathrm{kWh}$ from coal and fuel, respectively, 978 and $891 \mathrm{~g}$ of $\mathrm{CO}_{2}$ is rejected in atmosphere during combustion.

\section{Conclusion}

Different procedures with intensified extraction techniques and with adding a pretreatment step to the conventional extraction were studied for lipid recovery from Y. lipolytica IFP29 and compared in terms of extraction yield and lipid profiles with conventional maceration using Bligh and Dyer solvent mixture of chloroform and methanol $(1: 2, \mathrm{v} / \mathrm{v})$. Extraction by bead milling appears as the most efficient intensified extraction method and cold drying under pressure appears as the best pre-treatment method for lipid extraction from yeast, with a yield two times more than conventional maceration. The study of energyconsuming and environmental impact revealed that bead milling extraction are the best alternative for lipids recovery compared to a pretreatment by cold drying which appears to be the most energy-consuming technique. Ultrasound and microwave assisted extraction have shown a slight increasing of extraction yield, but 
Version définitive du manuscrit publiée dans / Final version of the manuscript published in :

Bioresource Technology (2016), Vol. 211, p. 190-199, DOI: 10.1016/j.biortech.2016.03.040

Journal homepage : www.elsevier.com/locate/biortech

present a difference in term of lipid profile, with degradation of DAG into FFA, while all the microbial oils extracted by other techniques have a similar profile. Kinetic study of extraction by bead milling demonstrated that breaking the wall of yeast cell is the key processing, and permit to enhance mass transfer of lipids from yeast to solvent.

\section{Acknowledgements}

This study was funded by French Government Investissement d'Avenir ANR PROBIO3 (2012-2020). Cassandra BREIL thanks the FIDOP/FASO funds (Fonds d' Action Stratégique des Oléagineux) from the French vegetable oil and protein production industry for her doctoral grant. Authors thank Isabelle Bornard from INRA PACA for her scientific help for scanning electron microscopy.

\section{References}

Beopoulos, A., Nicaud, J.-M., 2012. Yeast: a new oil producer? OCL 19, 22-28. Bermúdez Menéndez, J.M., Arenillas, A., Menéndez Díaz, J.Á., Boffa, L., Mantegna, S. Binello, A., Cravotto, G., 2014. Optimization of microalgae oil extraction under ultrasound and microwave irradiation: optimization of microalgae oil extraction using ultrasound and microwaves. J. Chem. Technol. Biotechnol. 89, 1779-1784.

Bligh, E.G., Dyer, W.J., 1959. A rapid method of total lipid extraction and purification. Can. J. Biochem. Physiol. 37, 911-917.

Boyd, A.R., Champagne, P., McGinn, P.J., MacDougall, K.M., Melanson, J.E., Jessop, P. G., 2012. Switchable hydrophilicity solvents for lipid extraction from microalgae for biofuel production. Bioresour. Technol. 118, 628-632.

Burja, A.M., Armenta, R.E., Radianingtyas, H., Barrow, C.J., 2007. Evaluation of fatty acid extraction methods for Thraustochytrium sp. ONC-T18. J. Agric. Food Chem. 55, 4795-4801.

Chuck, C.J., Lou-Hing, D., Dean, R., Sargeant, L.A., Scott, R.J., Jenkins, R.W., 2014. Simultaneous microwave extraction and synthesis of fatty acid methyl ester from the oleaginous yeast Rhodotorula glutinis. Energy 69, 446-454.

Das, A.K., Babylatha, R., Pavithra, A.S., Khatoon, S., 2013. Thermal degradation of groundnut oil during continuous and intermittent frying. J. Food Sci. Technol. 50, 1186-1192.

Dey, P., Maiti, M.K., 2013. Molecular characterization of a novel isolate of Candida tropicalis for enhanced lipid production. J. Appl. Microbiol. 114, 1357-1368.

Florentino de Souza Silva, A.P., Costa, M.C., Colzi Lopes, A., Fares Abdala Neto, E., Carrhá Leitão, R., Mota, C.R., Bezerra dos Santos, A., 2014. Comparison of pretreatment methods for total lipids extraction from mixed microalgae. Renewable Energy 63, 762-766.

Folch, J., Lees, M., Sloane, S.G.H., 1957. A simple method for the isolation and purification of total lipides from animal tissues. J. Biol. Chem. 226, 497-509.
Foltz, G., 2012. Algae Lysis with Pulsed Electric Fields. California State Polytechnic University, San Luis Obispo.

Gao, D., Zeng, J., Zheng, Y., Yu, X., Chen, S., 2013. Microbial lipid production from xylose by Mortierella isabellina. Bioresour. Technol. 133, 315-321.

Groenewald, M., Boekhout, T., Neuvéglise, C., Gaillardin, C., van Dijck, P.W.M., Wyss, M., 2014. Yarrowia lipolytica: safety assessment of an oleaginous yeast with a great industrial potential. Crit. Rev. Microbiol. 40, 187-206.

Herodež, Š.S., Hadolin, M., Škerget, M., Knez, Ž., 2003. Solvent extraction study of antioxidants from Balm (Melissa officinalis L.) leaves. Food Chem. 80, 275-282.

Huang, C., Chen, X., Xiong, L., Chen, X., Ma, L., 2012. Oil production by the yeast Trichosporon dermatis cultured in enzymatic hydrolysates of corncobs. Bioresour. Technol. 110, 711-714.

Khoomrung, S., Chumnanpuen, P., Jansa-Ard, S., Ståhlman, M., Nookaew, I., Borén, J., Nielsen, J., 2013. Rapid quantification of yeast lipid using microwave-assisted total lipid extraction and HPLC-CAD. Anal. Chem. 85, 4912-4919.

Milanesio, Juan Manuel, Medina-González, Y., Camy, S., Condoret, J.-S., 2013. Extraction of lipids from Yarrowia lipolytica. Chem. Technol. Biotechnol. 88, 378-387.

Montalescot, V., Rinaldi, T., Touchard, R., Jubeau, S., Frappart, M., Jaouen, P., Bourseau, P., Marchal, L., 2015. Optimization of bead milling parameters for the cell disruption of microalgae: process modeling and application to Porphyridium cruentum and Nannochloropsis oculata. Bioresour. Technol. 196, 339-346.

Pingret, D., Durand, G., Fabiano-Tixier, A.-S., Rockenbauer, A., Ginies, C., Chemat, F., 2012a. Degradation of edible oil during food processing by ultrasound: electron paramagnetic resonance, physicochemical, and sensory appreciation. J. Agric. Food Chem. 60, 7761-7768.

Pingret, D., Fabiano-Tixier, A.-S., Bourvellec, C.L., Renard, C.M.G.C., Chemat, F., 2012b. Lab and pilot-scale ultrasound-assisted water extraction of polyphenols from apple pomace. J. Food Eng. 111, 73-81.

Rawat, I., Ranjith Kumar, R., Mutanda, T., Bux, F., 2013. Biodiesel from microalgae: a critical evaluation from laboratory to large scale production. Appl. Energy 103, 444-467.

Spiro, M., Selwood, R.M., 1984. The kinetics and mechanism of caffeine infusion from coffee: the effect of particle size. J. Sci. Food Agric. 35, 915-924.

Vicente, G., Bautista, L.F., Rodríguez, R., Gutiérrez, F.J., Sádaba, I., Ruiz-Vázquez, R.M., Torres-Martínez, S., Garre, V., 2009. Biodiesel production from biomass of an oleaginous fungus. Biochem. Eng. J. 48, 22-27.

Wang, J., Zhang, B., Chen, S., 2011. Oleaginous yeast Yarrowia lipolytica mutants with a disrupted fatty acyl-CoA synthetase gene accumulate saturated fatty acid. Process Biochem. 46, 1436-1441.

Xie, J., Lin, Y.-S., Shi, X.-J., Zhu, X.-Y., Su, W.-K., Wang, P., 2013. Mechanochemicalassisted extraction of flavonoids from bamboo (Phyllostachys edulis) leaves. Ind. Crops Prod. 43, 276-282.

Zhang, N., Gardner, D.C.J., Oliver, S.G., Stateva, L.I., 1999. Genetically controlled cell lysis in the yeast Saccharomyces cerevisiae. Biotechnol. Bioeng. 64, 607-615.

Zhang, X., Yan, S., Tyagi, R.D., Drogui, P., Surampalli, R.Y., 2014. Ultrasonication assisted lipid extraction from oleaginous microorganisms. Bioresour. Technol. 158, 253-261.

Zhu, Q., Jackson, E.N., 2015. Metabolic engineering of Yarrowia lipolytica for industrial applications. Curr. Opin. Biotechnol. 36, 65-72. 